\title{
SOME OBSERVATIONS ON PEAK EXPIRATORY FLOW
}

\author{
BY \\ R. J. SHEPHARD \\ From the War Office, Chemical Defence Experimental Establishment, Porton Down, Wilts
}

(RECEIVED FOR PUBLICATION AUGUST 2, 1961)

The peak flow meter (Wright and McKerrow, 1959) was originally conceived as a simple portable method of estimating forced expiratory volume (F.E.V.). However, the correlation with F.E.V. and with maximum voluntary ventilation (M.V.V.) was not always very close, and the peak flow meter reading was therefore advocated as a measure of "ventilatory capacity" in its own right. The present paper reports some normal peak flow readings obtained with the Wright meter: such values are influenced not only by airway resistance but also by the pressure developed by the thoracic musculature, and the results obtained depend largely on co-operation from the patient. I have used peak flow readings, obtained before and after introduction of an external resistance, to calculate a value for airway resistance that is less dependent on subjective co-operation and muscular power. The frequency response characteristics of the Wright peak flow meter do not permit measurements with an external resistance; however, if peak flow readings are obtained by high frequency equipment, such as a screen pneumotachograph, and a small external resistance is used, the calculated airway resistance does not differ systematically from interrupter valve values.

\section{MethodS}

Peak Flow Measurement.-The peak flow has been defined by Wright and McKerrow (1959) as the highest flow rate sustained by a subject for at least $10 \mathrm{~m} . \mathrm{sec}$. In the present experiments, this parameter was measured by a standard commercial peak flow meter bought recently (serial No. 557), and also by a Y-shaped double-screen pneumotachograph of the type described previously (Shephard, 1957), but having a flow resistance of only $7 \mathrm{~mm}$. $\mathrm{HO}$ at $1,0001 . / \mathrm{min}$. flow.

Readings were obtained alternately with the two instruments, and after control values had been established, standard orifices of $8 \mathrm{~mm}$., $6 \mathrm{~mm}$., and $4 \mathrm{~mm}$. internal diameter were placed in turn in the mouthpiece, and peak flow readings repeated. Static calibration of the orifices with water manometer and piezometer ring showed resistances of $2.0,8.0$, and $28.0 \mathrm{~cm}$. $\mathrm{H} \mathrm{O} / 1$. $/ \mathrm{sec}$. at a flow of $0.5 \mathrm{l} / \mathrm{sec}$, , and a flow exponent of 1.80 to 1.85 in each case over the normal range of peak flows.

In view of the wide use of the Wright meter in field studies, the characteristics of the instrument were examined in some detail. The resistance of the meter to transient flows was substantially as described by Wright and McKerrow (1959) for steady flow conditions, amounting to $4 \mathrm{~cm}$. H O with peak flows of $300 \mathrm{l}$./min., and rising to $7 \mathrm{~cm} . \mathrm{H}_{2} \mathrm{O}$ with short puffs at 500 to $600 \mathrm{l} / \mathrm{min}$. (Fig. 1). This exceeds the resistance of the screen pneumotachograph by more than an order. At steady flow rates of $40-5001 . / \mathrm{min}$., delivered through a rotameter, the peak flow meter over-read by 50 to $70 \mathrm{l} . / \mathrm{min}$. (Fig. 2); this characteristic, which was recognized by Wright and McKerrow, is a consequence of the method of calibration used. Oscillating flows from a sine-wave pump (frequency 1-3 c/sec.) gave discrepancies of peak flow readings that were always as large as, and often larger than, those produced by steady flow. Wright's original instrument was calibrated "physiologically," a small group of subjects blowing alternately through a screen pneumotachograph and the peak flow meter. Using this method (Fig. 3), the present peak flow meter did not show a significant systematic error under normal operating conditions, though when the wave form was artificially blunted by introduction of an external resistance, significant systematic discrepancies resulted (see Table I). A technical fault of the peak flow meter was that with repeated use sufficient water vapour condensed in the compartment housing to jam the ratchet mechanism. This could probably be overcome by fitting a more air-tight seal between the ratchet and vane compartments. After about 1,000 measurements

TABLE I

PEAK FLOW METER READINGS INTRODUCING EXTERNAL RESISTANCE

\begin{tabular}{|c|c|c|}
\hline $\begin{array}{c}\text { Added External } \\
\text { Resistance } \\
\text { (cm. } \mathrm{H}_{2} \mathrm{O} / 1 . \text { 'sec.) }\end{array}$ & $\begin{array}{c}\text { Mean Discrepancy } \\
\text { 士S.E. } \\
\text { (1./min. A.T.P.S.) }\end{array}$ & $\begin{array}{c}\text { Percentage } \\
\text { Error }\end{array}$ \\
\hline $\begin{array}{r}0 \\
2 \\
8 \\
28\end{array}$ & $\begin{array}{r}-22 \pm 12 \\
+49 \pm 8 \\
+124 \pm 9 \\
+70 \pm 6\end{array}$ & $\begin{array}{l}-4 \cdot 2 \\
+14 \cdot 2 \\
+70 \\
+77\end{array}$ \\
\hline
\end{tabular}




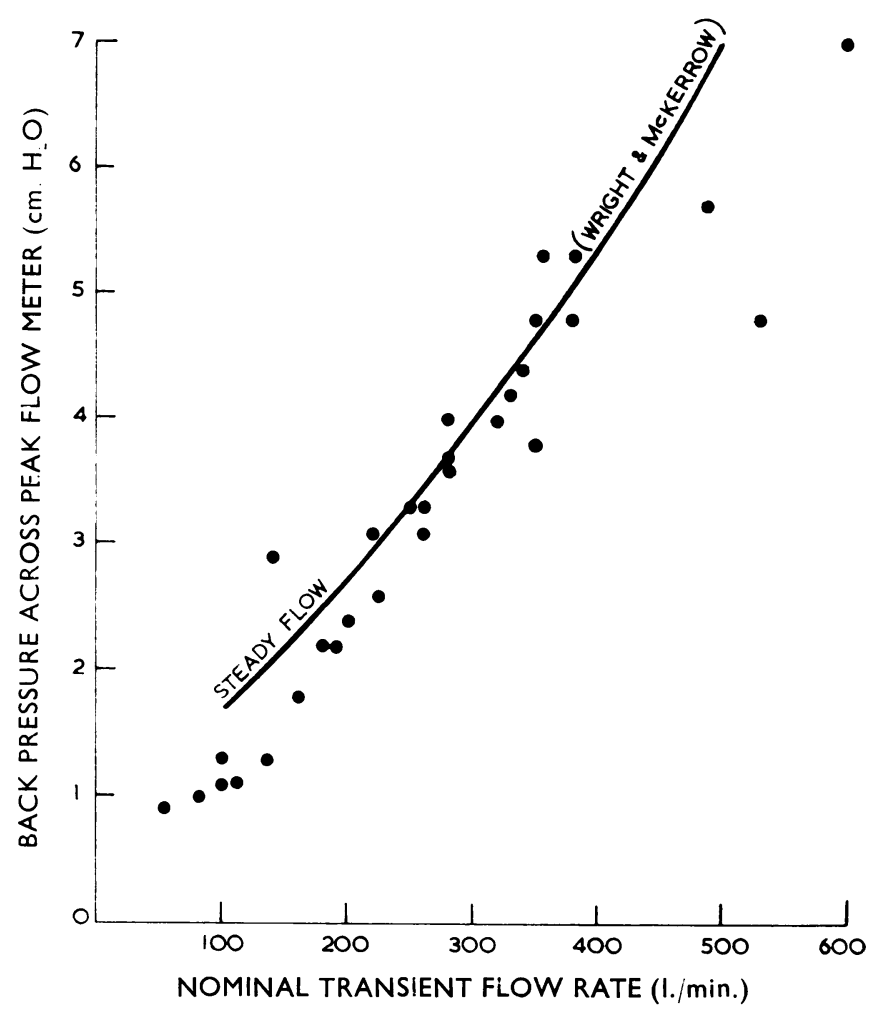

FIG. 1.-Flow resistance of Wright peak flow meter (transient flows).

the vane also showed such distortion that it had to be replaced.

Other ExPERIMENTAL Techniques.-Pulmonaty airway resistance was determined by interrupter valve (Clements, Sharp, Johnson, and Elam, 1959), both flow and interruption pressures being measured during the middle third of expiration (Shephard, 1959). The mean of ten successive estimates was taken.

Vital capacity and forced expiratory volume (1 sec.) were measured by means of a high frequency spirometer (Bernstein and Mendel, 1951). The highest of three successive readings was taken.

SUBJECTS.-All normal subjects were clinically and radiographically free of chest disease. Thirty males and eight females were drawn from the research and laboratory staff of a teaching hospital, and 58 males were volunteers from the fighting Services. All were of at least average physical fitness, but none was undergoing regular athletic training. The average tobacco consumption of the hospital staff (four cigarettes/day) was low compared with that of the Service men (13.5 cigarettes/day), and the Service volunteers had certain characteristic personality trends (Kemp and Shephard, in preparation); however, there is no evidence that the latter influenced peak flow readings. None of the normal subjects had had previous experience with the peak flow meter. Sixteen patients with emphysema, most of whom were severely disabled. were also tested. All these were diagnosed initially by Guy's Hospital Chest Clinic and showed the standard physiological criteria of emphysema. including a decrease of vital capacity and F.E.V. (the latter not responding to isoprenaline spray), and an increase in the slope of the single breath oxygen inhalation test.

\section{THEORY}

Calculation of Airway Resistance from Peak Flow.-It is assumed that the chest musculature can generate a constant pressure $P$, and that this is proportional to a power function of flow $F$. Under normal circumstances, pulmonary resistance $R_{i}$ is purely internal, and

$$
P=R_{i}\left(F_{1}\right)^{n}
$$

If the internal resistance $R_{i}$ is supplemented by an external resistance $R_{e}$, peak flow is reduced from $F_{1}$ to $F_{2}$, and

Thus,

$$
P=R_{i}\left(F_{2}\right)^{n}+R_{e}\left(F_{2}\right)^{n}
$$

$$
\frac{\left(F_{1}\right)^{n}}{\left(F_{2}\right)^{n}}=\frac{R_{i}+R_{e}}{R_{i}}
$$




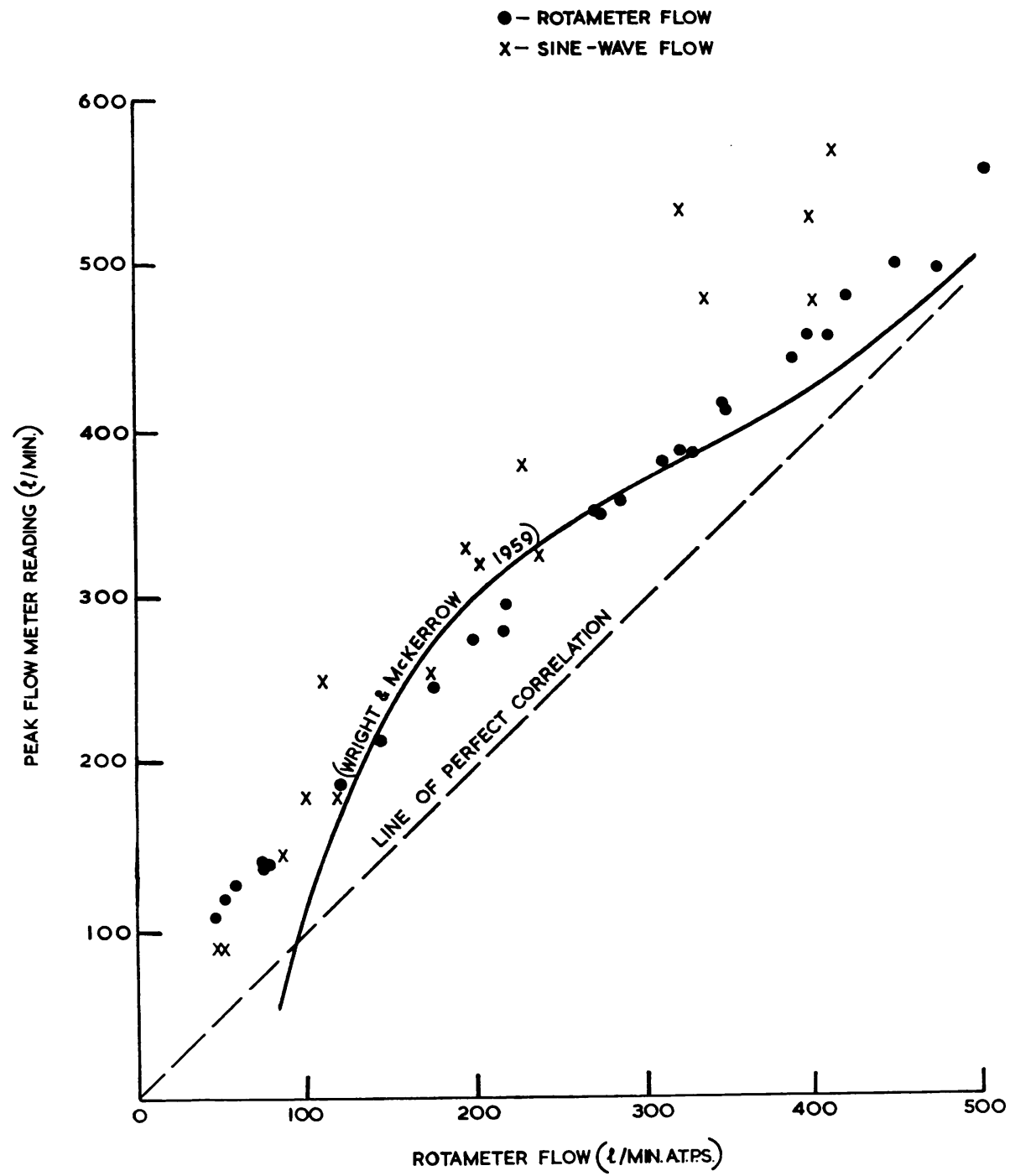

FIG. 2.-Steady flow and sine-wave flow calibration of peak flow meter.

and if $R_{e}$ is known, $R_{i}$ can be calculated from $F_{1}$ and $F_{2}$. The validity of the assumptions underlying this calculation is discussed on page 47.

\section{RESULTS}

1. Peak Flow Meter Readings in Normal SUBJECTS

(a) Technique of Measurement.-Repetition of the peak flow test at half-minute intervals gave increasing values for the first two to five puffs, a plateau for the next ten puffs, and then usually a gradual decline. Grouped results for the first 15 Service subjects are shown in Fig. 4.
The highest peak flow reading recorded in any subject exceeded the mean peak flow for the same subject by an average of $55.21 . / \mathrm{min}$. A.T.P.S. (S.D. $\pm 26.91 . / \mathrm{min}$., range $13-1081 . / \mathrm{min}$.). The mean peak flow on any one day was quite reproducible (coefficient of variation $4.5 \%$, S.D. of C.V. $\pm 2.8 \%$, range $2.2-13.7 \%$ ) ; the difference between mean values on successive days was somewhat larger $(8.8 \%$, S.D. $6.3 \%$, range $0.2-$ $29.4 \%$ ).

The effect of varying the initial chest position (normal inspiration in place of full inspiration) was tested in 22 subjects. As would be antici- 

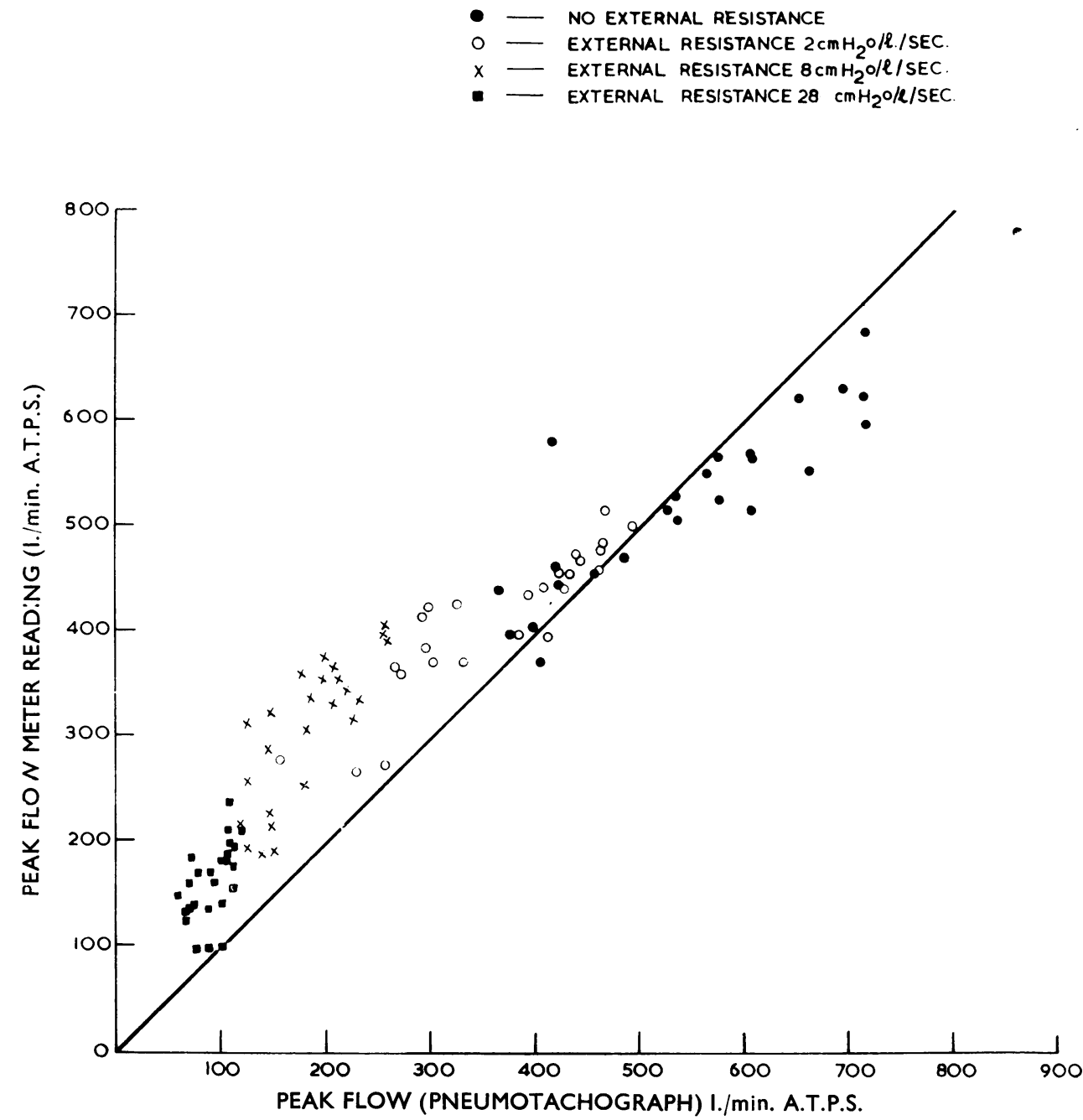

FIG. 3. - "Physiolozical" calibration of peak flow meter-alternate use of flow meter and screen pneumotachograph.

pated from the work of Hyatt, Schilder, and Fry (1958), the peak flow reading was significantly smaller with the shallower inspiration (mean \pm S.E. $488 \pm 6,573 \pm 10 \mathrm{l} . / \mathrm{min}$. respectively), and the coefficient of variation was significantly increased (mean \pm S.E. $5.3 \pm 0.7 \%$, $2.9 \pm 0.3 \%$ respectively).

(b) Normal Values.-The normal peak flow meter readings reported here are the mean of the sixth to fifteenth values obtained from a position of full inspiration. There was no significant difference between flow rates for the laboratory staff and the Service volunteers, and
TABLE II

\begin{tabular}{|c|c|c|c|c|c|}
\hline \multirow[b]{2}{*}{$\begin{array}{l}\text { Age } \\
\text { (yr.) }\end{array}$} & \multirow[b]{2}{*}{ Sex } & \multirow[b]{2}{*}{$\begin{array}{l}\text { No. } \\
\text { of } \\
\text { Sub- } \\
\text { jects }\end{array}$} & \multirow[b]{2}{*}{$\begin{array}{c}\text { Mean } \\
\text { Peak Flow } \\
\pm \text { S.D. } \\
\text { (1.'min. } \\
\text { A.T.P.S.) }\end{array}$} & \multicolumn{2}{|c|}{ Mean Peak Flow \pm S.D. } \\
\hline & & & & $\begin{array}{c}\text { Corrected to } \\
\text { Standing Height } \\
\text { of } 175 \mathrm{~cm} .^{*} \\
\text { (1./min. } \\
\text { A.T.P.S.) }\end{array}$ & $\begin{array}{l}\text { Corrected to } \\
\text { B.S.A. of } \\
\text { 1.78 m. } \\
\text { (1./min. } \\
\text { A.T.P.S) }\end{array}$ \\
\hline $\begin{array}{c}19-38 \\
40-49 \\
>50 \\
76 \\
16-29\end{array}$ & $\begin{array}{l}\mathbf{M} \\
\mathbf{M} \\
\mathbf{M} \\
\mathbf{M} \\
\mathbf{F}\end{array}$ & $\begin{array}{r}72 \\
11 \\
5 \\
1 \\
8\end{array}$ & $\begin{array}{c}533 \pm 70 \\
502 \pm 55 \\
515 \\
541 \\
414 \pm 48\end{array}$ & $\begin{array}{c}535 \pm 66 \\
510 \pm 55 \\
525 \\
551 \\
453 \pm 57\end{array}$ & $\begin{array}{c}525 \pm 63 \\
506 \pm 76 \\
498 \\
577 \\
485 \pm 59\end{array}$ \\
\hline
\end{tabular}

* Linear regressions, fitted by the method of least squares

Peak expiratory flow $=(-61+163)+(3 \cdot 42 \pm 1 \cdot 35)$ H1. I min.A.T.P.S. Peak expiratory flow $=(+120 \pm 115)+(223 \pm 63)$ B.S.A. I. $\mathrm{min}$ 


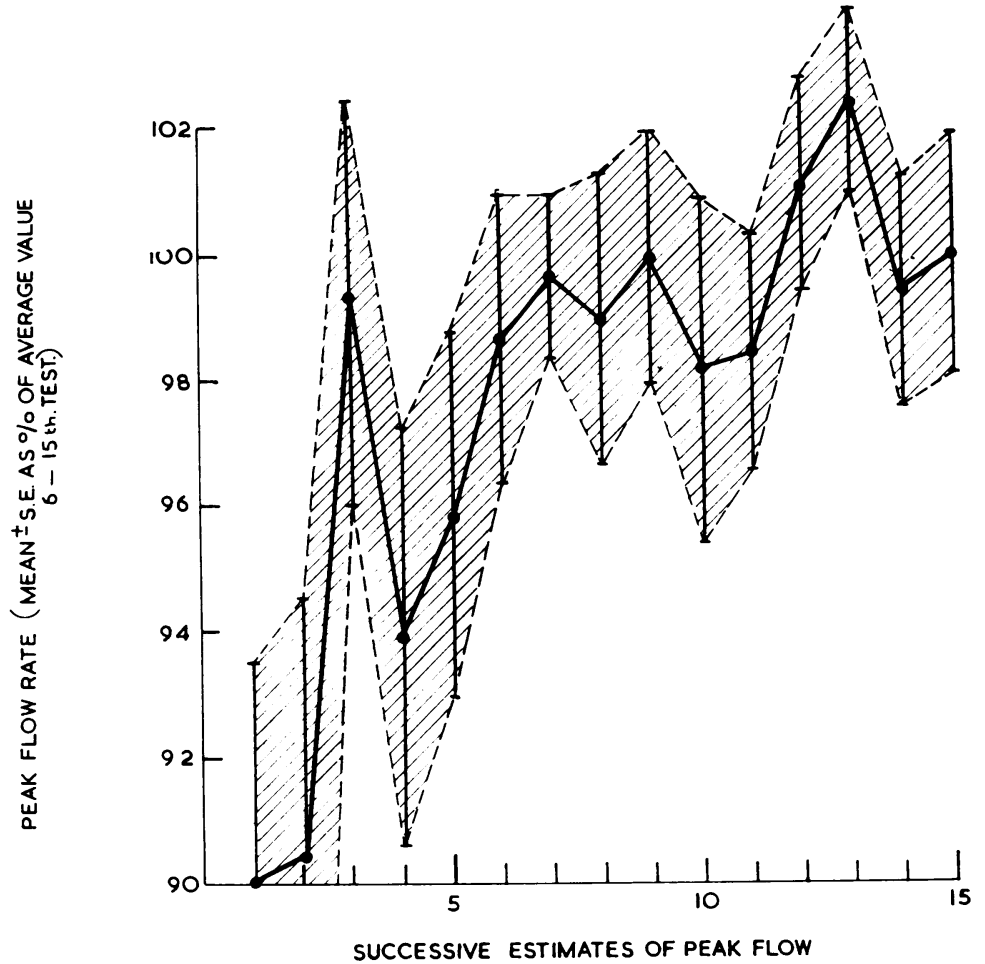

Fig. 4. -Peak flow (percentage of plateau value) at successive attempts.

the two populations are therefore considered together (Table II). In 72 men (16 laboratory staff, 56 Service men) aged 19-38 years, the distribution of values was as follows:

\begin{tabular}{c|c|c|c|c|c|c|c}
\hline $350-$ & $400-$ & $450-$ & $500-$ & $550-$ & $600-$ & $650-$ & 700 \\
399 & 449 & 499 & 549 & 599 & 649 & 699 & $1 . / \mathrm{min}$ \\
\hline 4 & 4 & 11 & 20 & 20 & 9 & 3 & 1 \\
\hline
\end{tabular}

Peak flow readings were significantly correlated with standing height and body surface area (B.S.A.), but not with age. The absence of correlation with age is probably due, at least in part, to choice of population (page 40). Peak flows were substantially smaller in female subjects, even after correcting for differences of body surface area.

(c) Correlation with Forced Expiratory Volume. -In the 16 laboratory staff aged 19-38 there was little correlation between peak flow and F.E.V. (Figs. 5 and 6). However, since the peak flow meter is intended to investigate impairment of breathing capacity, I widened the range of peak flow and F.E.V. readings by including patients with moderate to severe impairment of breathing capacity. When this was done, significant correlations could be demonstrated between peak flow and 1 sec. F.E.V. $(r=0.88 \pm 0.09, P<0.001)$ and between peak flow and 1 sec. F.E.V. expressed as a percentage of vital capacity $(\mathrm{r}=0.78 \pm 0.12, \mathrm{P}<0.001)$.

\section{Effect of External Resistance on Peak FLow}

With no external resistance, the screen pneumotachograph tracings of peak flow often showed a sharp peak, and sometimes sudden decelerations, suggestive of airway collapse (Fig. 7a and 7e), but with increasing resistance this was progressively flattened to a long plateau of relatively constant flow (Fig. 7b-d). As already noted, this alteration of waveform precludes the use of the Wright meter with an external resistance. Expressing 
- NORMAL SUBJECTS

$X$ - EMPHYSEMA CASES.

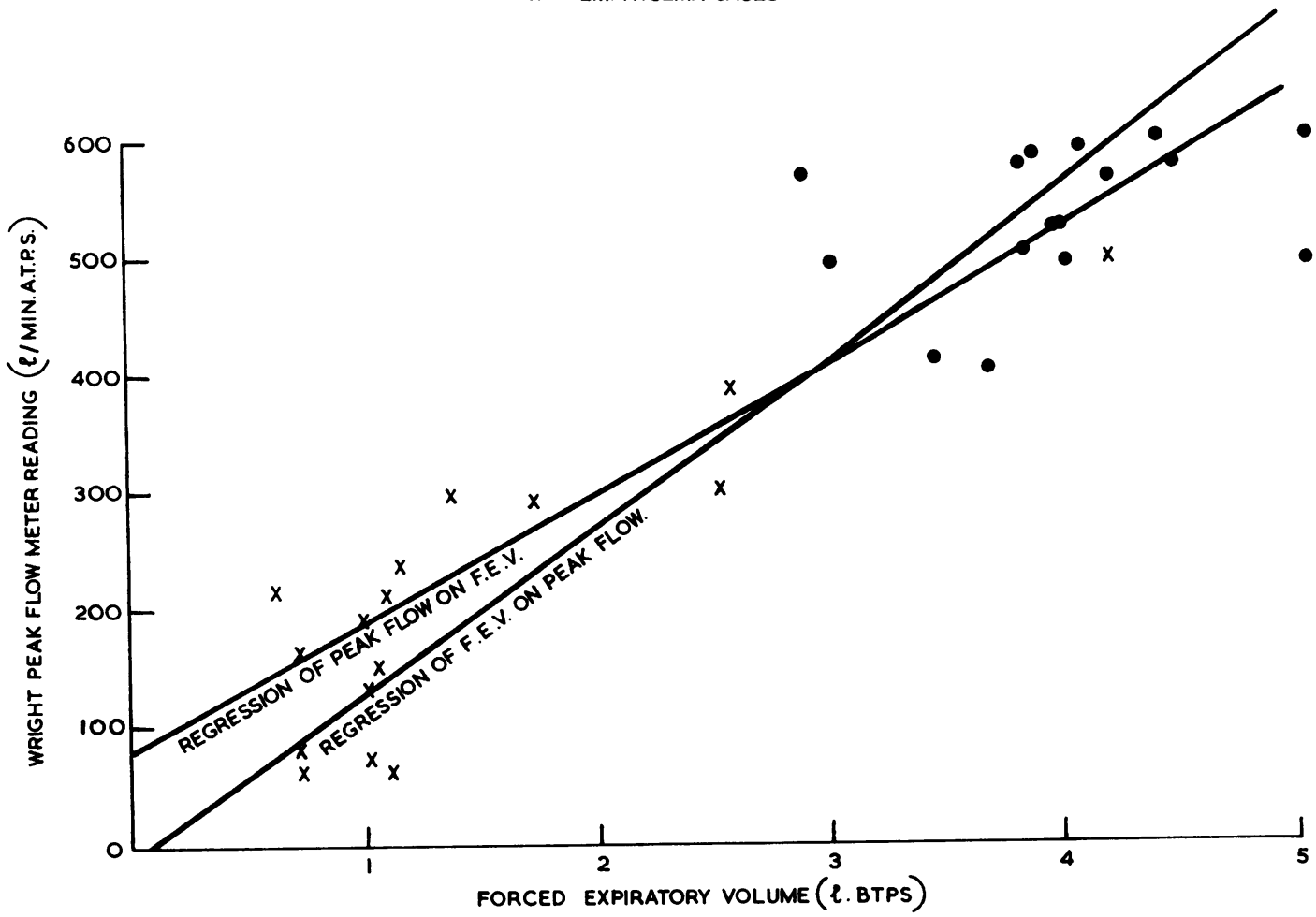

Fig. 5.-Correlation between peak flow and forced expiratory volume $(r=0.88 \pm 0.09)$.
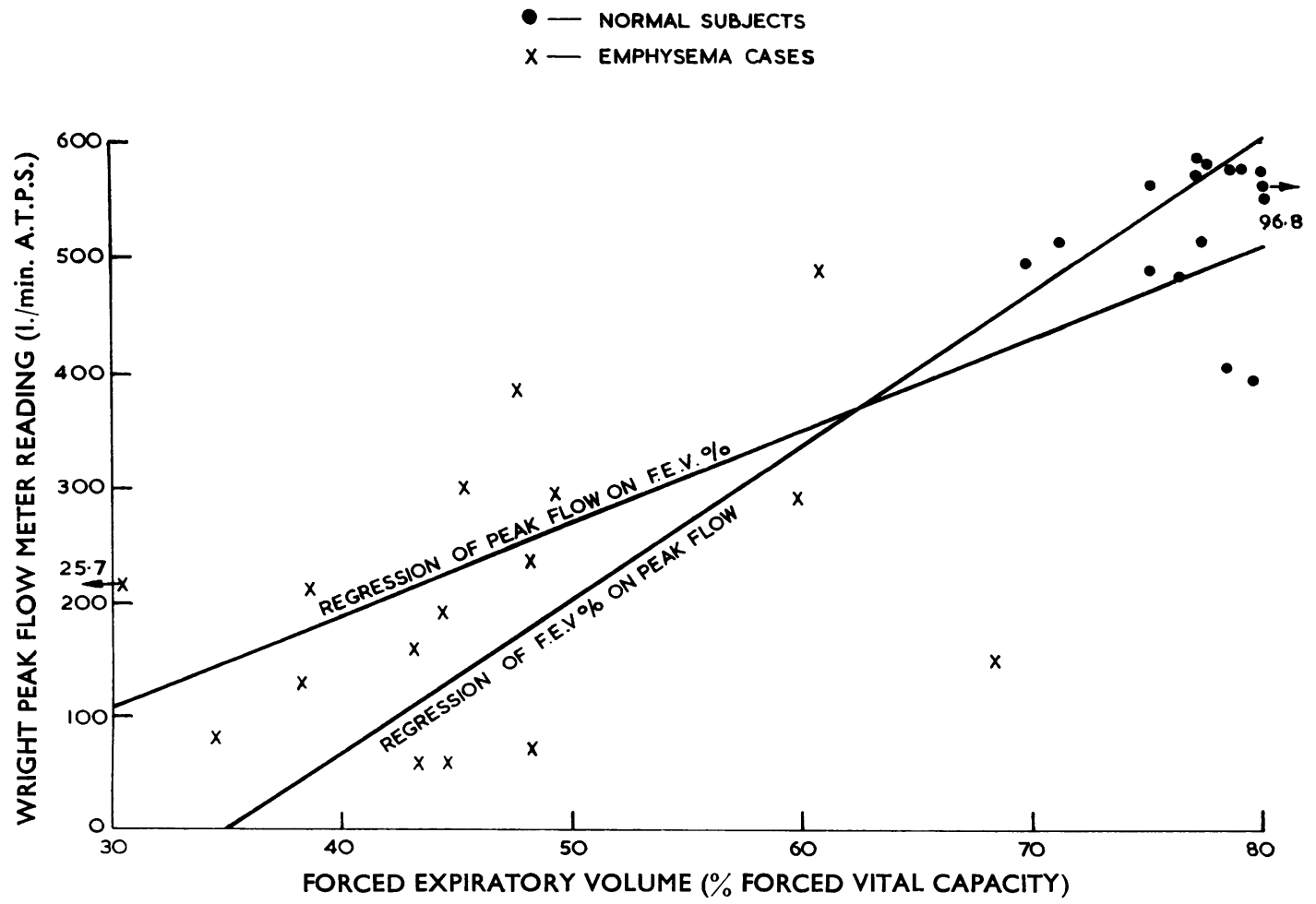

FIG. 6.-Correlation between peak flow and forced expiratory volume (\% of capacity). $r=0 \cdot 78 \pm 0 \cdot 12$. 


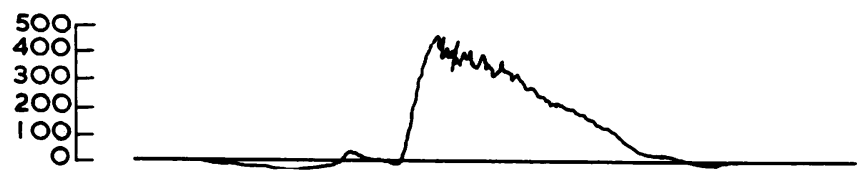

(a) NO EXTERNAL RESISTANCE
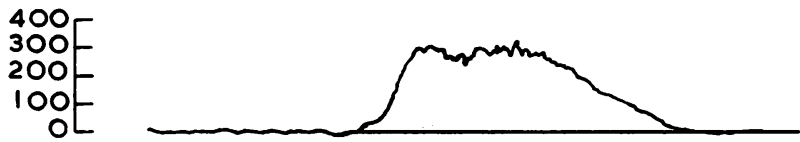

(b) EXTERNAL RESISTANCE $2 \mathrm{~cm} \mathrm{H}_{2} \mathrm{O} / \mathrm{\ell} / \mathrm{SEC}$.
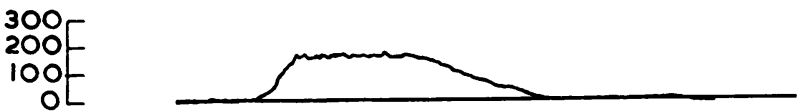

(c) EXTERNAL RESISTANCE $8 \mathrm{~cm} \mathrm{H} 2 \mathrm{O} / \mathrm{l} / \mathrm{SEC}$.

${ }^{300}{ }^{300}-$

(d) EXTERNAL RESISTANCE $28 \mathrm{~cm} \mathrm{H}_{2} \mathrm{O} / 2 / \mathrm{SEC}$.
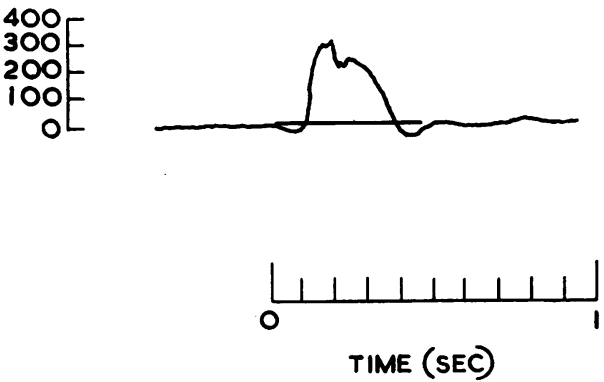

PEAK FLOW TRACING SHOWING

(c) SUDDEN DECELERATION OF FLOW SUGGESTIVE OF COLLAPSE OF AIRWAY

Fig. 7.-Effect of external resistance on form of peak flow tracing. (a) No external resistance, (b) external resistance $2 \mathrm{~cm}$. $\mathrm{H}_{2} \mathrm{O} / \mathrm{l}$. sec., (c) external resistance $8 \mathrm{~cm}$. $\mathrm{H}_{2} \mathrm{O}^{\prime}$ l. $/ \mathrm{sec}$., (d) external resistance $28 \mathrm{~cm} . \mathrm{H}_{2} \mathrm{O} / 1$. $/ \mathrm{sec}$., and $(e)$ to show sudden deceleration of peak flow suggestive of collapse of airway.

peak flow rate with no resistance as $100 \%$, external resistance reduced the screen pneumotachograph readings in 42 Service men as follows:

\begin{tabular}{c|c|c}
\hline $\begin{array}{c}\text { Resistance } \\
\text { (cm. HzO/1./sec.) }\end{array}$ & $\begin{array}{c}\text { Peak Flow } \\
\text { (\% Control) }\end{array}$ & S.E. \\
\hline 2 & 66.4 & \pm 3.2 \\
8 & 34.4 & \pm 1.3 \\
28 & 17.6 & $\mathbf{0 . 8}$ \\
\hline
\end{tabular}

3. Calculation of Airway Resistance from Peak Flow Readings

In 29 of the Service subjects, airway resistance calculated from the screen pneumotachograph peak flow readings at the three levels of external resistance was compared with resistance values determined by the interrupter valve. The mean, S.E., range, and detailed results for four subjects in which agreement between the two methods was poor are given below: 


\begin{tabular}{|c|c|c|c|c|}
\hline & \multirow{2}{*}{$\begin{array}{c}\text { Clements' } \\
\text { Interrupter } \\
\text { Valve } \\
\text { Values }\end{array}$} & \multicolumn{3}{|c|}{ Calculated Airway Resistance } \\
\hline & & $\begin{array}{c}\text { External } \\
\text { Resistance }\end{array}$ & $\begin{array}{c}\text { External } \\
\text { Resistance }\end{array}$ & $\mid \begin{array}{c}28 \mathrm{~cm} . \mathrm{H}_{2} \\
\text { External } \\
\text { Resistance }\end{array}$ \\
\hline$\underset{(n=29)}{\text { Mean }}$ & $\begin{array}{c}\left(\mathrm{cm} . \mathrm{H}_{2} \mathrm{O}\right. \\
1 . / \mathrm{sec} .) \\
2 \cdot 49\end{array}$ & $\underset{\left.1 . / \mathrm{sec}_{2}\right)}{\left(\mathrm{cm} . \mathrm{H}_{2} \mathrm{O} /\right.}$ & 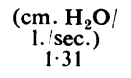 & $\begin{array}{c}\left(\mathrm{cm} . \mathrm{H}_{2} \mathrm{O} !\right. \\
1 . / \mathrm{sec} .) \\
1 \cdot 15\end{array}$ \\
\hline $\begin{array}{l}\text { S.E. } \\
\text { Range }\end{array}$ & $\begin{array}{c}0.17 \\
0.98-4.74\end{array}$ & $\begin{array}{c}0.23 \\
0.63-5.83\end{array}$ & $\begin{array}{c}0.11 \\
0.42-2 \cdot 73\end{array}$ & $\begin{array}{c} \pm 0 \cdot 10 \\
0 \cdot 29-2 \cdot 32\end{array}$ \\
\hline \multicolumn{5}{|c|}{$\begin{array}{l}\text { Difference between Clements' valve and calculated resistance, mean } \\
+S . E .\end{array}$} \\
\hline $\begin{array}{cc}\text { Subject } & \text { D } \\
. . & \text { Y } \\
. . & \text { S } \\
. . & \text { L }\end{array}$ & $\begin{array}{l}2 \cdot 38 \\
3 \cdot 19 \\
3 \cdot 01 \\
4 \cdot 74\end{array}$ & $\begin{array}{c}0.46+0.25 \\
4.78 \\
5.83 \\
1.11 \\
2.06\end{array}$ & $\begin{array}{c}1 \cdot 170.19 \\
1 \cdot 55 \\
2 \cdot 73 \\
0.45 \\
1 \cdot 76\end{array}$ & $\begin{array}{c}1 \cdot 32 \neq 0 \cdot 18 \\
1.41 \\
1.97 \\
0.51 \\
1.58\end{array}$ \\
\hline
\end{tabular}

With the lowest external resistance, there was a small and statistically insignificant difference between the two methods of the order to be expected from the known effect of a difference in alveolar volume on airway resistance (Shephard. 1959); however, the standard deviation of the difference $( \pm 1.34)$ was too large to attach rigid quantitative significance to the calculated airway resistance. In the two subjects with large positive errors (D and $Y$ ), the discrepancy was not confirmed by measurements with the larger resistances, suggesting poor co-operation by the subjects. In one patient with a large negative error (L), the interrupter valve resistance was very high and may have been in error.

As the external resistance was increased, significant systematic differences between the interrupter valve and calculated resistance values appeared (mean \pm S.E. of discrepancy for larger resistances $1.17 \pm 0.19$ and $1.32 \pm 0.18 \mathrm{~cm} . \quad \mathrm{H}_{2} \mathrm{O} / 1$. $/ \mathrm{sec}$. respectively).

\section{DISCUSSION}

\section{Peak Flow as an Independent Measure of Ventilatory CAPACITY}

(a) Use of Peak Flow Meter.-It is first necessary to distinguish between absolute values for peak flow, as determined by high frequency devices such as the screen pneumotachograph, and the more approximate values obtained by portable flow meter under conditions where complicated electronic apparatus cannot be used. The readings of the Wright meter are critically dependent on the pattern of the applied flow, and when breathing through an external resistance the recorded flow grossly exceeds the true value even in normal subjects. The " physiological " method of calibration used by Wright and McKerrow largely overcame this difficulty for the subjects tested $(20$ normal adults, 10 children, and 20 cases of pneumoconiosis) under normal operating conditions, but where the peak flow pattern is altered the problem imposed by the response characteristics of the instrument remains.

Despite this limitation and some basic weaknesses in mechanical design (see page 39), its portability commends the peak flow meter in situations where extreme light-weight equipment is essential. It is both smaller and lighter than devices for measuring timed ventilatory capacity (Shephard, Thomson, Carey, and Phair, 1958) and t med airway resistance (Shephard, 1959), and is more convenient to use than the Warring-Siemsen venturi tube* for measuring maximum breathing capacity.

(b) Subjectivity.-All peak flow readings are essentially dependent on the co-operation of the subject. The reproducibility of values in normal healthy subjects compares favourably with other clinical tests, but when the patient is trying to get compensation, or does not like uncomfortable experimental procedures, the apparent peak flow may be much reduced. The same criticism applies in other tests of ventilatory effort such as the F.E.V. and M.V.V., but lack of co-operation is more easily detected in sustained expiratory efforts. In theory, the timed airway resistance is not liable to systematic subjective error, but in practice problems can arise in nervous or uncooperative patients through failure to grip the mouthpiece sufficiently tightly, and (in the Clements' interrupter valve) through tensing of the chest muscles (Shephard, unpublished data).

(c) Normal Variation.-Despite the reproducibility of peak flow meter readings in a given subject, there is a wide range of normal values, both within a population and also from one population to another. In an agricultural area, Higgins (1957) reported that $95 \%$ of the men aged 25-35 years had peak flow values of 300-800 1./ min., with a mean value of $684 \mathrm{l} . / \mathrm{min}$. Wyss and Hadorn (1952), using their pneumometer on unspecified normal subjects, showed a mean peak flow of $5701 . / \mathrm{min}$. at about 27 years, falling to $380 \mathrm{l} . / \mathrm{min}$. at 70 years.

Others using the Wright meter have also found lower mean values than Higgins. Lockhart, Smith. Mair, and Wilson (1960) reported a mean of 537 $1 . / \mathrm{min}$. in 105 men (hospital staff and symptomfree flax workers of unspecified age), and Tinker (1961) a mean of $6221 . / \mathrm{min}$. at age 30-34 years, falling to $517 \mathrm{l} . / \mathrm{min}$. at age $55-59$ years in workers at a bus repair depot. The series of Mork (1960) 
is not comparable, as this included men with cough and sputum persisting for less than three months ; nor are the pneumotachograph measurements of Shephard (1955) and Bouhuys (1956), showing ranges of $183-427 \mathrm{l} . / \mathrm{min}$. and $144-4741 . / \mathrm{min}$. in normal laboratory staff, since these were obtained during forced vital capacity expirations. However, even discounting these last three series, the range of normality is wide.

The coefficient of variation is an important factor limiting the diagnostic value of any test (Shephard and Turner, 1959); estimates for the peak flow meter vary, probably with the homogeneity of the population tested, from $13.1 \%$ in the present series to $30 \%$ in the series of Lockhart et al. (1960). There is probably an increase in the coefficient of variation with age, Tinker (1961) showing values of $13.6-16.7 \%$ in men under 50 , and $19.0-21.7 \%$ in men aged $50-59$ years. The lower estimates (13-15\%) are greater than for F.E.V. (8.7\%), comparable with M.V.V. (14.3\%), and less than for pulmonary resistance $(25 \%$, Shephard, to be published).

(d) Sensitivity to Increased Resistance.-An external resistance equal to airway resistance $\left(2 \mathrm{~cm} . \mathrm{H}_{2} \mathrm{O} / 1\right.$. $/ \mathrm{sec}$.) has a relatively small effect on peak flow meter readings (mean reduction \pm S.D. $23.9 \pm 8.7 \%$ ). Tiffeneau and Drutel (1949) and Gaensler (1951) have shown that in normal subjects the same resistance reduces F.E.V. by $38 \%$. In disease states such as emphysema, bronchial collapse may occur when only a small fraction of the F.E.V. has been expelled (Hyatt et al., 1958). In these circumstances, the F.E.V. is influenced little by an external resistance, although sensitivity to changes of internal (airway) resistance is probably retained. In the case of the interrupter valve, the apparent airway resistance is increased by $56-100 \%$, depending on details of technique (Shephard, to be published). If changes of internal resistance had similar effects on the four tests, their relative value as discriminators of increased resistance ( \% change with resistance/coefficient of variation $\%$ ) would be as follows:

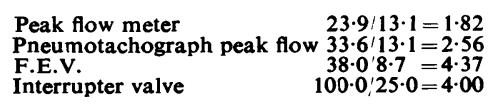

In fact, the peak flow meter may have a somewhat better performance than these figures suggest, since it is not certain that the calibration of the peak flow meter is disturbed by a change of internal resistance. On the other hand, the discriminatory capacity of the F.E.V. may also be greater when the increase of resistance is internal, since in diseases such as emphysema the disability is characterized not by a reduction of peak flow but by a failure to sustain this high flow rate for an adequate period (Leuallen and Fowler, 1955 ; Bouhuys, 1956 ; Hyatt et al., 1958).

2. Calculation of Airway Resistance from Peak Flow Readings

\section{(a) Assumptions of Method}

(i) CONSTANT MAXIMUM INTRATHORACIC PRESSURE.-Although it has been assumed that the maximum intrathoracic pressure is unaltered by external resistance, it has been known for some time (Shephard, 1956; Milic-Emili and Petit, 1959) that the shape of the chest pressure/volume diagram is modified by changes in the speed of expiration. This is due partly to changes in the efficiency of muscular contraction and the lung volume at which maximum pressure is developed, and partly to the onset of unpleasant symptoms of Valsalva type when pressure is maintained. However, the effect of an external resistance in the physiological range is not very great. Agostoni and Fenn (1960) found an increase of some $13 \mathrm{~cm}$. $\mathrm{H}_{2} \mathrm{O}$ in the maximum pressure developed when expiring through a tube of $6 \mathrm{~cm}$. length and $8 \mathrm{~mm}$. internal diameter (probable resistance $\cong 3.2 \mathrm{~cm} . \mathrm{H}_{2} \mathrm{O} / 1$. $/ \mathrm{sec}$.).

(ii) CONSTANT INTERNAL RESISTANCE.-Although it has been assumed that airway impedance is purely resistive, and that this resistance is not modified by an external resistance, yet errors arise from capacitative and inductive components of impedance as total resistance is increased and expiration is slowed. DuBois, Brody, Lewis, and Burgess (1956) have shown that such phenomena become important at frequencies of less than $5 \mathrm{c} / \mathrm{s}$, and the waveform falls well below this frequency in those experiments where an external resistance has been added (Fig. 7).

Further, as shown by Fry (1958) and Campbell (1959), maximum flow is limited over the latter part of a rapid expiration by the tendency of the airway to collapse. In normal subjects, peak flow either with or without an external resistance is not primarily dependent on this factor, which might be more important in conditions such as emphysema, where airway collapse commences when only a small fraction of the vital capacity has been expired.

(iii) CONSTANT FLOW EXPONENT N.-At the flow rates under discussion $(100-600 \mathrm{l} / \mathrm{min}$.), turbulence is present throughout those parts of the airway that contribute significantly to total 
internal resistance (Ainsworth and Shephard, 1960). However, the exponent $\mathrm{n}$ probably varies from 1.7 to 2.0 , according to the structure of the turbulent flow.

(b) Value of Method.-In comparison with the Clements' interrupter valve data, the airway resistance is somewhat under-estimated by the peak flow method. The back pressure across the two instruments is roughly comparable at operative flow rates (Clements' valve $6 \mathrm{~cm} . \mathrm{H}_{2} \mathrm{O}$ at 11 ./ sec. ; peak flow meter $7 \mathrm{~cm}$. $\mathrm{H}_{2} \mathrm{O}$ at 8-10 l./ $\mathrm{sec}$.), and some of the discrepancy with modest external resistances is probably due to the difference of lung volume in the two tests (mid expiration, compared with near full inspiration). Larger external resistances apparently reduce flow by more than would be anticipated from the simple theoretical treatment of page 40 leading to a marked under-estimate of internal (airway) resistance. Possibly blunting of the expiratory waveform by the external resistance increases the importance of non-resistive components of total pulmonary impedance when the external resistance is introduced. Despite the problems that arise when a large external resistance is added, the calculation of airway resistance does commend itself as a means of eliminating the subjective element from peak flow readings, and it is unfortunate that the response characteristics of the Wright meter preclude the use of this approach under field conditions.

Even if peak flow readings are translated into airway resistance values, there remains the important objection that resistance is estimated at only one point in the respiratory cycle (peak flow) and, as Leuallen and Fowler (1955) and Bouhuys (1956) have pointed out, the typical abnormality in conditions such as asthma and emphysema is an increase of resistance late in the course of expiration. It is true that peak flow meter values show a fair correlation with forced expiratory volume in patients with increased airway resistance, and the method must therefore be accepted as giving a semi-quantitative index of the combined subjective and objective limitation of ventilation. However, except in conditions where extremely light-weight equipment is essential, apparatus measuring F.E.V. or airway resistance over the entire cycle is to be preferred.

\section{SUMMARY}

The response characteristics of the Wright flow meter are critically evaluated, and some factors determining mean values and variation of peak flow in normal subjects are described.
There is little correlation between peak flow and forced expiratory volume unless the range of values is extended to include a big reduction of forced expiratory volume.

External resistance causes a progressive reduction of peak flow, and also an alteration of the flow waveform that causes erroneous readings of the Wright flow meter. If the peak flow rate with external resistance is measured by high frequency recording apparatus, it is possible to calculate pulmonary airway resistance from the data. eliminating much of the subjectivity of the peak flow measurement. However, the clinical significance of the results is still limited because (i) values are determined for only the first part of expiration, and (ii) the standard deviation of results is large. As the external resistance is increased, systematic errors also arise from the non-resistive components of total pulmonary impedance.

The data used in Figs. 5 and 6 were obtained in conjunction with Dr. A. Thornton, of the Department of Experimental Medicine, Guy's Hospital. I am much indebted to him for this information, and also to Mr. M. Frost, of this Establishment. for his technical assistance.

\section{REFERENCES}

Agostoni, E., and Fenn, W. O. (1960). J. appl. Physiol., 15, 349.

Ainsworth, M., and Shephard, R. J. (1960). British Occupational Hygiene Society, Symposium on Inhaled Particles and Vapours, Oxford, 1960.

Bernstein, L., and Mendel, D. (1951). Thorax, 6, 297.

Bouhuys, A. (1956). Pneumotachografie. M.D. thesis, Amsterdam University.

Campbell, E. J. M. (1959). J. appl. Physiol., 14, 153.

Clements, J. A., Sharp, J. T., Johnson, R. P., and Elam, J. O. (1959) J. clin. Invest., 38, 1262.

DuBois, A. B., Brody, A. W., Lewis, D. H., and Burgess, B. F. (1956). J. appl. Physiol., 8, 587.

Fry, D. L. (1958). Phys. in Med. Biol., 3, 174.

Gaensler, E. A. (1951). Amer. Rev. Tuberc., 64, 256.

Higgins, I. T. T. (1957). Brit. med. J., 2, 1198.

Hyatt, R. E., Schilder, D. P., and Fry, D. L. (1958). J. appl. Physio!. $13,331$.

Leuallen, E. C., and Fowler, W. S. (1955). Amer. Rev. Tuberc., 72 , 783.

Lockhart, W., Smith, D. H., Mair, A., and Wilson, W. A. (1960). Brit. med. J., 1, 37.

Milic-Emili, G., and Petit, J. M. (1959). Riv. Med. aero. spaz., 22 85.

Mork, T. (1960). Ph.D. Thesis, University of London.

Shephard, R. J. (1955). Thorax, 10, 258.

(1956). R.A.F. Flying Personnel Research Ccmmittee Report, FPRC 956.

- (1957). J. Physiol. (Lond.), 135, 98.

- (1959). Ibid., 145, 459.

- Thomson, M. L., Carey, G. C. R., and Phair, J. J. (1958). J. appl. Physiol., 13, 189.

and Turner, M. E. (1959). Thorax, 14, 300.

Tiffeneau, R., and Drutel, P. (1949). J. franc., Méd. Chir. thor., 3, 401. Tinker, C. M. (1961). Brit. med. J., 1, 1365.

Wright, B. M., and McKerrow, C. B. (1959). Ibid., 2, 1041.

Wyss, F., and Hadorn, W. (1952). Progr. Allergy, 3, 290. 